\title{
Explorando la agencia de las mujeres encarceladas a través de sus experiencias amorosas
}

\author{
Estibaliz de Miguel Calvo \\ Universidad del País Vasco \\ estibaliz.demiguel@ehu.eus
}

Recepción: 08-06-2016

\section{Resumen}

El presente trabajo explora la agencia de las mujeres encarceladas a través de sus experiencias emocionales, una agencia caracterizada por la redefinición de la propia identidad y por las decisiones en la vida emocional, que resultan disruptivas de las lógicas carcelarias. La base de este análisis es la investigación cualitativa con entrevistas semiestructuradas y observación participante desarrolladas en el departamento de mujeres de la cárcel de Nanclares de Oca (Álava). El amor de pareja constituye uno de los ejes sobre los que se articula la resistencia a las consecuencias del encarcelamiento y la supervivencia emocional, también sobre los que se articulan significados de la vida en prisión y redefiniciones del yo de las protagonistas. Por un lado, la experiencia amorosa de pareja puede ser entendida como una transgresión tras los barrotes, una forma de unión e intimidad en un lugar en que prima la separación y la distancia de los seres queridos, una forma de transcender el tiempo de encierro y proyectarse hacia un futuro esperanzado, aunque solo sea de manera precaria. Por otro lado, siendo el amor en la sociedad occidental contemporánea una experiencia de validación del propio yo y de libertad individual, ofrece unas posibilidades simbólicas particulares para las mujeres encarceladas, quienes portan un fuerte estigma social y carecen de libertad. La relación amorosa de pareja se convierte así en fuente de identidad positiva, en vía de acceso a un éxito social construido en condiciones de estratificación social.

Palabras clave: amor; cárcel; género; mujeres presas; emociones; poder; estratificación social; identidad; criminología; mujer 
Abstract. Exploring the agency of incarcerated women through their experiences of love

This article explores the agency of incarcerated women through their emotional experiences; an agency characterised by the redefinition of one's identity and decisions in the realm of emotions, which are disruptive of prison logics. The analysis is based on qualitative research using semi-structured interviews and participant observation conducted in the Nanclares de Oca prison of Álava, Spain. The love of a partner constitutes one of the pillars of resistance to the pain of imprisonment and emotional survival. Experiences of love also constitute a way to articulate the meaning of prison life and redefine the self of the participants. On the one hand, the love of a couple can be understood as a transgression behind bars, a way of connecting to others and experiencing intimacy in a place characterised by the logics of separation and distance from significant others. It is also a way of transcending the period of incarceration and imagining a hopeful future, even if it is a precarious alternative. On the other hand, being in love in contemporary Western society is a means of self-validation and experiencing freedom, which has a particular symbolic value for incarcerated women, who are stigmatized and lack freedom. Partner relationships thus become a source of positive identity and a way to succeed in conditions of social stratification.

Keywords: love; prison; gender; women in prison; emotions; social stratification; identity; power; criminology; woman

\section{Sumario}

Introducción 4. Investigación sobre las relaciones

1. Mujeres encarceladas, la identidad en pugna

2. Rastreando la agencia en prisión

3. La experiencia amorosa, entre los ideales contemporáneos y las subjetividades de género amorosas de las mujeres encarceladas

5. Luna habla de su pareja

Conclusiones

Referencias bibliográficas

\section{Introducción}

Según el último informe de la Secretaría General de Instituciones Penitenciarias, en 2014 la población presa en el Estado español era de 51.383, de cuya cifra un 7,8\% eran mujeres, un total de 4.343 (Secretaría General de Instituciones Penitenciarias, 2015). Más allá del dato bruto concreto, hay que destacar que esta tasa de encarcelamiento femenino del 7,8\%, que se mantiene relativamente estable en el tiempo, es la más alta de la Unión Europea (Aebi et al., 2015). A pesar de esta alta presencia proporcional de mujeres entre rejas y de las numerosas discriminaciones a que son sometidas (Almeda, 2003, 2005, 2007; Del Val-Cid y Viedma Rojas, 2012; Almeda y Ballesteros Pena, 2015), la investigación de esta realidad en nuestro contexto aún no ha cristalizado en un cuerpo académico que pueda dar cuenta de las diferentes implicaciones que tiene el encarcelamiento femenino (Almeda et al., 2012; De Miguel, 2014). 
En estas circunstancias, apenas se han indagado las posibilidades de resistencia frente al encierro por parte de las mujeres.

La cárcel es una institución total (Goffman, 1961) y un lugar privilegiado para analizar las relaciones de poder (Foucault, 1975) y las formas de control social a las mujeres. No obstante, también es un lugar de resistencia a esos mecanismos de poder. En la época actual, esta resistencia dentro de las cárceles no está marcada primordialmente por la orientación política y colectiva, sino más bien por formas individualizadas, no ideologizadas ni politizadas. Diversas autoras sitúan la identidad como eje principal de resistencia a los daños que causa la prisión (pains of imprisonment), que a menudo se refiere a un ejercicio de poder dirigido a socavar el sentido del yo de las presas, de moralizarlas y reeducarlas para que ejerzan las funciones que se consideran «apropiadas a su sexo", tal y como describiremos más adelante. Sostengo que las mujeres encarceladas intentan mantener la integridad de sí y revertir los efectos negativos de la identidad deteriorada construida por los diferentes agentes disciplinarios. El amor es un pilar fundamental sobre el que se articula esta resistencia. Tener a alguien en prisión por quien suspirar y con quien proyectarse hacia el futuro resulta un acicate para salir adelante, aunque ello suponga insertarse en un marco de relaciones de género normativo, al menos en primera instancia. Esto es lo que se pretende mostrar en el presente artículo.

En base a la exploración de las experiencias amorosas de las mujeres encarceladas, a través del trabajo de campo con 49 entrevistas seimiestructuradas y observación participante dentro de un departamento carcelario de mujeres, mi argumento es que las relaciones de pareja dentro de prisión son un recurso para resistir a las consecuencias del encierro, en la medida que rompen las lógicas de separación y desencuentro, y en la medida que constituyen también un recurso socialmente valorado. Debido a las connotaciones que el amor de pareja adquiere en nuestra sociedad occidental actual como espacio de libertad, vía de «salvación» y «escape», esta experiencia resulta especialmente atractiva en contextos de encierro. Al constituir una fuente de validación del yo, el amor de pareja es el elemento reparativo de la identidad deteriorada, ya que permite incluirse en un paradigma socialmente compartido y valorado colectivamente. De esta manera, las mujeres encarceladas atenúan la estigmatización y la exclusión social a la que son sometidas, insertándose en marcos de sentido amoroso que enfatizan la valía personal y el sentido de formar parte de una utopía compartida.

El artículo consta de cinco apartados. Primeramente, paso a describir los rasgos del castigo penitenciario a mujeres basado en regímenes de feminidad patriarcal, donde la referencia es «la Mujer» idealizada en base a rasgos de género, pero también de clase social, etnia y procedencia geográfica. Así, la identidad se perfila como un terreno de pugna por excelencia entre el poder y sus resistencias. En segundo lugar, trato las posibilidades de agencia de las mujeres dentro de prisión, para pasar a analizar, en tercer lugar, los significados sociales del amor que puedan hacer de esta experiencia un recurso valioso tras los barrotes y que puedan hacer entender la inclinación 
de las presas hacia la experiencia amorosa, como consecuencia del proceso de subjetivación de género a través del amor. En cuarto lugar, se describe la investigación sobre las experiencias amorosas de las encarceladas, el trabajo de campo y los perfiles de las participantes. $Y$, en quinto lugar, se desarrollan los resultados más relevantes en lo referente al amor como recurso de resistencia a las consecuencias del encierro y como fuente positiva de identidad a través de un relato de vida.

\section{Mujeres encarceladas, la identidad en pugna}

Los estudios sobre mujeres encarceladas han realizado importantes aportaciones acerca de la comprensión de las formas de control y poder generizado que se expresan en la cárcel. En prisión, el poder se ejerce con unos marcados rasgos de género, los cuales permiten entender la definición patriarcal de «la Mujer» y la reacción social ante la transgresión de las expectativas de género. Esto permite afirmar a Marcela Lagarde, en su obra Los cautiverios de las mujeres, que las presas concretan la prisión de todas. Ellas encarnan el cautiverio femenino, en cuanto falta de libertad, en el sistema patriarcal: «El análisis de las presas da luz sobre las prisiones diversas en que viven todas las mujeres» (Lagarde, 2005: 642). Pero veamos cómo estas sanciones se concretan en las mujeres criminalizadas en el marco de la institución penitenciaria.

Las investigaciones sobre mujeres encarceladas se han centrado en dos aspectos interrelacionados en la cuestión del castigo formal dirigido a ellas. Por un lado, los procesos de criminalización, es decir, cómo llegan algunas delincuentes a ser encarceladas y otras no. Y, por otro lado, cómo están funcionando los resortes de género, junto con la clase social y el grupo étnico, en las políticas penitenciarias, es decir, cómo es el régimen de castigo para ellas.

En cuanto a los procesos de criminalización, la cárcel excluye principalmente a colectivos que ya poseían rasgos de exclusión social (Cruells e Igareda, 2005), puesto que, de manera general, las presas habían experimentado alguno antes de su encarcelamiento. La criminalización de la pobreza (Manzanos, 1991) y, especialmente, la criminalización de las mujeres extranjeras y migrantes (Ribas et al., 2005; Naredo, 2005; Martín-Palomo et al., 2005; Ribas y Martínez, 2003; Castillo y Ruiz, 2010), pertenecientes a minorías étnicas, gitanas en nuestro caso (Barañi, 2001; Imaz y Martín-Palomo, 2007), y consumidoras de drogas de baja extracción social (De Miguel, 2015; Gañán y Gordon, 2001; Malloch, 2000), es una constante en el mundo occidental, y se aprecia en la sobrerrepresentación de estos colectivos también en nuestras cárceles. Esto queda en evidencia cuando se observa el patrón delincuencial que es perseguido y criminalizado, ya que la inmensa mayoría de las presas se encuentra en dicha situación por delitos característicos de los grupos de bajo nivel socioeconómico, de modo que el tráfico de droga en pequeña escala y los delitos contra la propiedad suman el $71,4 \%$ de los cometidos por mujeres (Secretaría General de Instituciones Penitenciarias, 2015). Ello indica un ensañamiento contra estos colectivos y, en el caso de las mujeres, el importante 
impacto de las políticas punitivas de drogas, por las cuales se penaliza a quienes consumen drogas y a los últimos eslabones de la cadena de un tráfico feminizado (Almeda et al., 2012; Giacomello, 2013; Comisión Global de Políticas sobre Drogas, 2014).

Los perfiles sociales de las mujeres criminalizadas indican una posición subordinada de género que intersecciona con otras variables de discriminación (clase social, etnia y procedencia geográfica) (De Miguel, 2016a), tanto en el ámbito público como en el privado. En el ámbito público, se ha remarcado su bajo nivel de instrucción, una débil posición en el mercado de trabajo y reducidos ingresos económicos, así como su importante papel en el ámbito doméstico y privado. En su mayoría, son madres en solitario y otorgan un importante peso a las relaciones de pareja (Miranda, 2002; Cruells y Torrens, 2004; De Miguel, 2008; Almeda, 2003, 2006; Manzanos y Balmaseda, 2003; Del Val-Cid y Viedma Rojas, 2012; Mapelli, 2012). Asímismo, las experiencias de violencia de género en pareja y de abusos sexuales contra ellas son tanto cuantitativa como cualitativamente relevantes (Cruells et al., 2005).

En cuanto a las formas de castigo de las mujeres, las obras de la criminología crítica feminista han puesto de manifiesto que las pobres que delinquen encarnan lo "obyecto", en la medida en que transgreden las normas de género $y$, por tanto, son las que entran en el radio de acción de las políticas penales y penitenciarias, esto es, son las identificadas como delincuentes y más fácilmente encarceladas (Larrauri, 1994). Desde el advenimiento de la disciplina en el ámbito anglosajón, las estudiosas de la materia pusieron el acento en la necesaria lectura de género que permite desvelar la labor de diferentes instituciones sociales (Iglesia, familia y estado) en la construcción esencializada de «la Mujer» y en el control social desplegado sobre aquellas que lo transgreden (Carlen y Worrall, 1987; Carlen, 1983, 1988, 1998; Chesney-Lynd y Rodriguez, 1983; Chesney-Lynd, 1986). Las mujeres identificadas como delincuentes son descritas como el «negativo de la foto» de «la Mujer» por diversos agentes sociales como los legisladores (Smart, 1977), en el sistema de justicia criminal (Worrall, 1990) y en el sistema penitenciario. En la medida en que el delito es asociado con la masculinidad (Messerschmidt, 1993, citado en Bernard, 2012), como acción, iniciativa y transgresión, ellas son concebidas como monstruosas, como «no-mujeres», ya que se comportan más como hombres que como las pasivas, cuidadoras y cumplidoras de las normas que se supone han de ser.

Elisabet Almeda ha sido la primera autora que ha trasladado estos análisis al contexto del Estado español. En su libro Mujeres encarceladas, analiza las explicaciones sexistas sobre la delincuencia femenina, que se remontan a Lombroso y Ferrero, los «padres» de la antropología criminal:

[L]as delincuentes tienen cualidades de la criminalidad masculina y, a más a más, las peores características femeninas: astucia, rencor, falsedad. En definitiva, pensaban que eran una combinación «antinatural» de los dos sexos; tenían invertidos los rasgos femeninos de las mujeres "normales», que son reservadas, maternales, dóciles y apáticas sexualmente. (Almeda, 2003: 18) 
Estas ideas, que asumen unas bases biológicas inmutables y confunden entre el sexo y el género, permanecen, según la autora, en las formas de funcionamiento de los agentes penitenciarios, de manera que el tratamiento en nuestras prisiones está enfocado hacia la domesticidad de las mujeres, las infantiliza y busca su feminización. Estas concepciones, por tanto, tienen una aplicación práctica en las formas de control que se despliegan durante el encarcelamiento, donde el tratamiento y la monitorización del comportamiento es más agudizado que para los hombres. Se ejerce una intervención más encaminada a la "feminización» de las mujeres presas que a prestar oportunidades para su «reinserción» (Heidensohn, 2000; Cruells e Igareda, 2005). El encarcelamiento para ellas está fuertemente marcado por los discursos o "regímenes de feminidad", que buscan regular su comportamiento a través de tres mecanismos de control: el monitoreo de su apariencia, el trabajo y la regulación de sus conductas (Bosworth y Carrabine, 2001). Si estos son rasgos característicos de las políticas penitenciarias españolas respecto a las mujeres, ello se hace aún más patente en las formas de control propias de los polémicos Módulos de Respeto, que se basan en maneras más sutiles de control, que incluyen el autocontrol y el control entre iguales por parte de otras compañeras (Almeda y Ballesteros Pena, 2015). En cualquier caso, las investigaciones estatales e internacionales coinciden en afirmar que las mujeres están sometidas a mayor control y a monitorización cotidiana, así como a mayor medicalización (Cruells et al., 2004), y que sufren una falta de atención a sus necesidades en función de sus perfiles de mujeres sostenedoras del hogar o como mujeres violentadas.

En definitiva, la identidad es un elemento central en el disciplinamiento penitenciario femenino y su estigmatización es una forma de ejercicio de poder de las instituciones penales. Según Goffman (1963), el estigma es un defecto, una falla o una desventaja que produce descrédito. La persona que posee el estigma no es considerada totalmente humana, con lo que se reducen de esta manera sus posibilidades de vida y se condiciona su interacción, tanto por parte de los demás como por parte de una misma. Desde una perspectiva de género, no solo se juzga socialmente de distinta manera el incumplimiento de la norma por parte de un hombre que por parte de una mujer (Juliano, 1998: 121), sino que ellas son estigmatizadas en función de diferentes categorías. Como he señalado en el presente apartado, son objeto de esa «indeseable diferencia» en la medida en que se desvían del mandato patriarcal que las define como serespara-otros, dependientes y carentes de libertad (Lagarde, 2005).

La transgresión de las mujeres identificadas como delincuentes no viene únicamente de lo que Carlen ha denominado ruptura del "pacto de género», sino también de la ruptura del «pacto de clase social» (Carlen, 1988). No en vano, las mujeres criminalizadas provienen de estratos sociales bajos o muy bajos, no alcanzan los estándares femeninos definidos por las élites socioeconómicas y su modelo de familia no responde al patrón burgués de «hombre ganador de pan» / «mujer ama de casa». De hecho, en muchas ocasiones, han delinquido como estrategia para salir de sus situaciones de privación (Bhavnani y Davis, 2007; Ribas et al., 2005). Si predomina la visión estigmatizada que 
«no reconoce a las personas afectadas la capacidad de actuar, decidir o evaluar por sí mismas» (Juliano, 2006: 28-29), será muy difícil apreciar rasgos de agencia en sus condiciones sociales.

Precisamente, los análisis de la criminología crítica feminista de las décadas de 1970 y 1980 han sido criticados por su visión estructuralista, que pone un excesivo enfoque en la capacidad del poder disciplinario de imponerse y en los regímenes de feminidad de la institución carcelaria. Se les ha acusado de moverse en una concepción binaria de dominación y resistencia, dejando en un más que segundo plano cuestiones relativas a la agencia de las mujeres presas y presentándolas como "víctimas ideales», (Fili, 2013: 4). Veamos si, a través de las propuestas epistemológicas y teóricas feministas de corte postestructuralista que se han desarrollado en los últimos tiempos, es posible apreciar la capacidad de acción de las mujeres encarceladas articulada con las relaciones de poder institucionales.

\section{Rastreando la agencia en prisión}

Rastrear la agencia de las mujeres encarceladas requiere de unas herramientas teóricas que nos permitan ir más allá de lo que se ha venido conceptualizando como resistencias en prisión, que han tenido primordialmente un marcado carácter político, colectivo y un planteamiento ideológico explícito. Si hoy en día las cárceles no se caracterizan primordialmente por las luchas organizadas ni conscientes, la tentación sería pensar que, por ello, no hay resistencias al poder institucional, que la actitud es pasiva y sumisa por parte de las mujeres que se encuentran en prisión.

Dolores Juliano (1998) afirma que el problema subyace en la perspectiva epistemológica con que nos aproximamos al objeto de estudio, puesto que a menudo asume que las mujeres de sectores populares son receptoras pasivas de una cultura que les asigna un papel subalterno, olvidando así que ellas desarrollan de manera continua estrategias de subversión y evitación de las imposiciones del sistema. En esta misma línea, Imaz (2007: 194) dice: «Un enfoque victimista supone negarles el derecho a ser vistas como sujetos capaces de decidir, de diseñar una estrategia, no como meros instrumentos de fuerzas que las superan, sino como sujetos que actúan utilizando los recursos que tienen a su alcance y que muchas veces combinan de forma muy creativa».

Entendiendo la subcultura carcelaria de las mujeres como una forma de subcultura femenina de sectores populares (Juliano, 1992) podemos pensar que, a diferencia de las demandas explícitas del feminismo, ellas priorizan los logros concretos y a corto plazo, donde la aparente aceptación de los modelos impuestos y la reelaboración de los mismos es una de las tácticas que ponen a disposición. El reto se encuentra en conceptualizar el poder no como algo dado de una vez para siempre, que emana de las instituciones o de las estructuras sociales, sino como algo que se recrea constantemente, y que, por tanto, da lugar al desliz, al cambio, a la inversión, al giro y a otras formas, en definitiva, a la resignificación (Butler, 1997; Foucault, 1975). Se trata de ir más allá de la 
dicotomía entre víctimas pasivas y resistencias activas para adentrarnos en los múltiples niveles que están operando en las relaciones sociales dentro de prisión y cómo estas se negocian, tal y como sugiere Fili (2013: 18): «En diálogo con la institución, todos los participantes negocian y constituyen la definición de la situación en que se encuentran. Esta interacción entre los sujetos puede crear el potencial para la resistencia o la conformidad».

En su reconceptualización de los conceptos de empoderamiento y agencia de las mujeres delincuentes, Pollack (2008) critica los enfoques individualistas, ya que pueden llevar a culpabilizar a la víctima por cuestiones que provienen de diferentes formas de opresión, y reclama que se tengan en cuenta los contextos de violencia y de abuso en que han vivido muchas mujeres encarceladas. Las razones para cometer un delito no estarían en la «baja autoestima», sino en contextos de privación y victimización. No obstante, ellas practican su capacidad de agencia también en condiciones de opresión, ejerciendo lo que la autora denomina «agencia relacional», que pone el acento en el carácter relacional del poder. A este respecto, es posible apreciar la capacidad de agencia si vamos más allá de la concepción de víctima que esencializa, fija una identidad y paraliza la capacidad de acción, y hablamos más de una experiencia de victimización que no anula sus capacidades. Esta diferencia también ha sido hecha por Lagarde (2005) cuando distingue entre «condición»y «situación» de víctima.

Por lo apuntado hasta ahora, podemos entender que los estudios feministas de orientación postestructuralista ofrecen una base teórica sobre la que pivotar la reflexión sobre la agencia de las mujeres encarceladas e ir definiendo en qué aspectos se concreta esa agencia.

Mageehon (2008), en su descripción acerca de las formas en que las mujeres encarceladas negocian el poder, reconoce la fragilidad de su posición respecto al poder penal y al del personal carcelario, pero aprecia que ellas actúan adoptando formas de conformidad y resistencia pasiva, que resuena en las tácticas que Scott (2000) denomina «infrapolítica de los dominados». Mageehon se centra en el espacio educativo en prisión y aprecia negociaciones de poder entre el profesorado y el alumnado, según las cuales las mujeres presas alumnas de la escuela eligen guardar silencio, interrumpir la dinámica de la clase, no asistir o contestar al profesorado de varias formas, entre otras acciones. Se trata de unas conductas que, en su búsqueda por socavar a la autoridad, pueden ser autodestructivas, por tanto, no están exentas de ambigüedad.

Ciertamente, nos encontramos ante un objeto de estudio problemático, no carente de incertidumbres, ya que aún no se ha logrado un consenso a la hora de definir con nitidez el campo en que nos movemos. Bosworth usa el término agente para expresar dos atributos de las mujeres encarceladas: por una parte, su papel de sujetos y, por otra, su capacidad de actuar y, concretamente, de actuar negociando poder y resistiendo. En este marco, la autora afirma que la resistencia es una de las formas que adopta la agencia, que, a su vez, ilumina los intentos de las protagonistas por distorsionar las relaciones de poder en la escala micro, pero teniendo en cuenta, al mismo tiempo, el statu quo. Bosworth y Carrabine (2001) profundizan en la descripción de la resistencia a través de tres 
apuntes. Primero, matizan que esta no siempre resulta visible para una audiencia, es decir, que puede referirse a cuestionamientos de la autoridad enmarcados en lo personal o íntimo. Segundo, advierten que no se puede dar por supuesto que las personas que no parecen cuestionar la autoridad estén aceptando la legitimidad de la institución. Y, tercero, proponen alejarse de concepciones de la resistencia muy asociadas al uso de la violencia y a la protesta explícita.

Otra aportación importante de las autoras es que ponen el acento en diversos ejes de interseccionalidad a la hora de entender las estrategias de resistencia de las mujeres encarceladas. Estas estrategias de resistencia reflejan sus posiciones de género, raza y sexualidad, entre otras, y construyen las diferentes opciones a través de esas experiencias atravesadas por relaciones de poder. Las autoras observan formas de contestar al poder a través del peinado entre las afroamericanas. En el campo de la sexualidad, las relaciones lésbicas u homosexuales son entendidas no solo como una forma de sobrellevar las penurias del encarcelamiento, sino también como manera de resistir a construcciones estereotipadas de género, por las cuales las mujeres son, por definición, heterosexuales.

La dimensión interseccional de la agencia está presente en la reflexión sobre la capacidad femenina de resistir al poder en general y, sobre todo, de aquellas mujeres criminalizadas. Así, Bernard introduce la expresión crear identidad (doing identity) para explicar la criminalidad femenina y describir los esfuerzos de los individuos, especialmente de las mujeres marginalizadas, para navegar a través de las estructuras de poder y de la multiplicidad de sistemas de opresión $^{1}$. Esta pretende ser una propuesta alternativa a la creencia de que existen estructuras sociales de carácter estable, fijo y sólido, y que las vidas de las mujeres pueden ser explicadas de manera esencialista y atendiendo a un solo eje de análisis. En mi propio trabajo (De Miguel, 2016a), tomo esta idea de «crear identidad» para analizar el relato de vida de una mujer consumidora de droga que es encarcelada e ilustrar las múltiples y complejas relaciones que se pueden establecer entre los ejes de etnia, clase social, género, consumo de drogas y delito. En este sentido, enfatizo la noción de agencia en su versión interseccional usando el término de Huijg (2012) agencia interseccional para comprender que las decisiones que las protagonistas toman en esa maraña de relaciones de poder no siempre son unívocas ni predecibles y que, por tanto, no se puede homogeneizar su análisis en conceptos estancos.

Fili (2013), en su análisis de la agencia de las mujeres en prisiones griegas, encuentra que las estrategias para aliviar malestares causados por la prisión se enmarcan en fórmulas de preservación de la identidad, orientadas a resistir a la esencialización de la mujer. Esto supone tomar en serio los significados en la interacción con la institución carcelaria y la dimensión dialógica que ello implica. En esta línea, Ribeiro y Mendoza analizan el cuerpo preso tatuado como

1. «The concept of doing identity is then introduced to describe the unique attempts of individuals, particularly marginal- ized women, to navigate through power structures and multiple systems of oppression» (Bernard, 2012: 4). 
espacio discursivo, como recurso de comunicación en que pueden escribirse, distinguir sus cuerpos unos de otros y expresar protestas: «Frente a ese sistema carcelario omnidisciplinar y totalitario, el preso encuentra en su cuerpo una manera de hablar» (2013: 301). De esta manera, a través del tatuaje, las personas presas realizan un ejercicio de reconfiguración y redefinición de sí mismos y de su relación con los demás, que les permite afirmar su existencia como seres sociales y establecer lazos con otra gente. Sostengo que esta lectura sobre el tatuaje de las personas presas puede ser extrapolada a la experiencia amorosa, ya que también permite una redefinición del yo y de las relaciones sociales.

Nari et al. (2000) encuentran que las mujeres tratan de sobrevivir material, subjetiva y emocionalmente al encierro a través de fórmulas donde la afectividad cumple un papel importante. El ámbito emocional también es terreno abonado para articular estrategias, lo cual implica entender los sentimientos no como algo de una vez y para siempre, sino concebir que cuentan con una plasticidad que los actores y las actrices sociales barajan de manera más o menos consciente (Esteban, 2010: 241). El ámbito amoroso puede ser una estrategia en sí misma que permita transcender a situaciones de escasez material y emocional: «En el día a día, en la imperiosa necesidad de reconstruir una cotidianidad, quizás la estrategia más fuerte dentro de la cárcel sea amar. Amar a una pareja, amar a una hija, amar a una madre, amar a un padre, amar a una hermana. No importa que no lo sean, no importa que el vínculo dure lo que dura el encierro" (Nari et al., 2000: 17).

Sin embargo, las autoras no describen a través de qué mecanismos el amor se convierte en recurso para la resistencia en prisión. Eso es lo que tratamos de desgranar aquí. Para ello, considero que es útil tener en cuenta la propuesta de Bosworth (1999), quien incluye la negociación de la noción de feminidad como estrategia de resistencia. Para la autora, las mujeres en prisión cooptan una definición de feminidad pretendidamente universalista y homogeneizante, para apropiarse de ella y extender sus márgenes hasta que puedan incorporarse a sus propias experiencias. Esta es una forma de agencia, dado que toman el control sobre la propia definición de feminidad realizando una propuesta alternativa. Uno de los terrenos de cooptación más importantes es la maternidad. Muchas se reivindican como «buenas madres» frente a la etiqueta institucional de «malas madres» $y$, de esta forma, se autoafirman frente a la definición hegemónica de mujer y madre. Pero no solo actúan a través del rol de madre, sino también a través de identidades propias de la feminidad, como esposas, novias y amantes. Y aquí es donde se articula la redefinición de la dimensión identitaria con el campo emocional, que pretendo desarrollar a través de la profundización en las implicaciones de la experiencia amorosa de pareja.

Este papel de las relaciones amorosas en prisión se ha explicado como una forma metafórica de «liberación» (De Miguel, 2016b), lo cual puede ser útil para entender en qué medida se trata de un recurso disponible en prisión que resulta valioso y que contiene unas connotaciones metafóricas densas en ese contexto. Pero sostengo que es posible ensayar otras metáforas que nos permitan apreciar los diferentes significados implicados en las relaciones amorosas 
de las mujeres encarceladas, así como las diferentes formas de resistencia identitaria, social y emocional, teniendo en cuenta la variedad de significados de la experiencia sentimental de pareja en nuestro mundo actual.

\section{La experiencia amorosa, entre los ideales contemporáneos y las subjetividades de género}

La propuesta analítica que aquí se presenta toma aportaciones de dos tipos de teorías sobre el amor. Por un lado, el estudio del papel del amor en los procesos de individualización y subjetivación generados en el contecto occidental, unas aproximaciones de corte eminentemente sociológico. Y, por otro, aquellas teorías orientadas al papel del amor en la generación y en la perpetuación de las desigualdades de género (Esteban et al., 2005), donde los estudios de género y/o feministas han desempeñado un papel primordial.

En cuanto a la primera línea, a pesar de que el encuentro entre las emociones y la sociología ha sido más bien "frío" (Smart, 2007), existe un creciente interés por las relaciones amorosas, ya que empiezan a ser apreciadas como un componente central para la vida social y personal, por su papel destacado en la configuración de la subjetividad del individuo moderno y por tratarse de un configurador de las prácticas sociales (Esteban et al., 2005; Esteban, 2010). Diversos autores de nuestra disciplina han centrado su atención en la relación entre los procesos de modernidad tardía y las relaciones amorosas (Giddens, 1992; Bauman, 2003; Evans, 2003; Gómez, 2004), poniendo de relieve el papel de la intimidad y la vida amorosa para los individuos, hasta tal punto que Beck y Beck-Gernsheim (1990) han llegado a entender el amor como «la nueva religión laica de nuestro tiempo». En un momento histórico de creciente individualización y secularización en nuestra sociedad occidental, donde los lazos tradicionales propios de las sociedades premodernas han perdido su peso, el amor ha tomado una posición central para la vida de las personas.

El «encantamiento» ya no proviene de la religión institucionalizada, sino de las relaciones de pareja del ámbito de la intimidad: «Cuantos más referentes se pierden para la estabilidad, más dirigimos hacia la relación con la pareja la necesidad que sentimos de dar sentido y arraigo a nuestra vida» (1990: 93). Langford (1999) enfatiza el significado del amor de pareja como "salvación», sentido de vida, felicidad o forma de trasladarse fuera de la rutina diaria a un lugar especial. En este contexto, se da cabida a un nuevo protagonismo de los actores sociales y de la agencia humana. La elección personal es un elemento clave, puesto que acentúa la libertad como valor imprescindible de nuestra sociedad que se recrea en las relaciones humanas (Giddens, 1992; Illouz, 2012).

En esta línea de análisis de la relación del amor con los procesos y las características de la sociedad actual, Eva Illouz, en El consumo de la utopía romántica (1992), afirma que la relación de pareja está relacionada con los nuevos estilos de consumo del capitalismo avanzado, donde se construye un imaginario colectivo del romance en que se desdibujan las diferencias de clase social y género: «El amor romántico se ha convertido en un elemento íntimo e 
indispensable del ideal democrático de opulencia que acompañó el surgimiento de los mercados masivos, con lo cual ofrece una utopía colectiva que trasciende y atraviesa todas las clases sociales» (1992: 18). De esta manera, participar en lo que podríamos llamar "consumo del amor» es una forma de inclusión social, es decir, una vía de participación en esa utopía colectiva, aunque el acceso de esos bienes romantizados y la mercantilización del amor romántico de que habla la autora sigue sin estar al alcance de todas las personas. En este punto que señala Illouz, es donde se expresa que «la organización social del amor no se estructura solo en términos de patriarcado, sino también, y en igual o mayor medida, en términos de la clase socioeconómica» (1992: 42).

Otra aportación fundamental de la autora para el análisis que aquí nos ocupa se encuentra en su trabajo ¿Por qué duele el amor? (Illouz, 2012), donde ella responde que el amor duele en las condiciones sociales actuales porque otorga un sentido de valía personal. De esta manera, si desaparece la pareja hace desaparecer el sostén psicológico básico personal: «Sentir amor equivale a superar una sensación común de invisibilidad, y lleva a que la persona se sienta única y aumente el sentido de valor propio. El incremento de la autoestima que implica el amor sería entonces un elemento central de dicho sentimiento» (Illouz, 2012: 150-151). Este es uno de los ejes clave para comprender la inclinación de las mujeres encarceladas hacia las relaciones de pareja, sobre todo teniendo en cuenta que su sentido de valía personal se encuentra socavado, debido al estigma de no-mujeres que portan, tal y como hemos descrito anteriormente.

En cuanto a la segunda línea de análisis, de carácter más multidisciplinar, se ha puesto de manifiesto el papel crucial del amor en la conformación de subjetividades de género, definidas como diferenciadas, opuestas, complementarias y jerarquizadas, a través de discursos y prácticas en diferentes órdenes de la vida, desde los discursos de la existencia cotidiana hasta las descripciones de los saberes expertos (Medina Doménech, 2013b, 2013a). En esta línea, Lupton (1998) analiza la diferenciación en la construcción de un discurso sobre las emociones acerca de hombres y mujeres en el mundo occidental, representados en los modelos de la «mujer emocional» y el «hombre sin emociones». Los estereotipos culturales de la vida cotidiana y los medios de comunicación asocian a las mujeres con una mayor capacidad de sentir los afectos y de expresarlos, entendiendo que son ellas quienes están más familiarizadas con el mundo de las emociones y quienes se encargan de la gestión emocional de la familia. Hochschild (1979), por su parte, describe las «normas emocionales», que se construyen de manera diferenciada para hombres y mujeres, en una división sexual según la cual se asigna a ellas la gestión emocional de la vida privada.

De esta manera, el ámbito de la pareja y del amor aparece como central en la existencia femenina (Bosch y Ferrer, 2002, 2013; Lagarde, 2000, 2008; Esteban y Távora, 2008), en contraste con los hombres, para quienes el ámbito sentimental queda relegado a un segundo plano. "[Las mujeres son] seres para el amor, seres de amor", dice Lagarde (2000: 347). Para ellas, la experiencia amorosa es definitoria de su identidad de género, de manera que estar en una 
relación de pareja se tiende a asociar con ser socialmente valiosas y, por contra, estar solteras se relaciona con tener algún tipo de fallo (Langford, 1999). Así, el amor es «aquello que nos hace hombres y mujeres» (Esteban et al., 2005; Esteban, 2009, 2010, 2011), el escenario por excelencia donde se performan (Butler, 2007) las feminidades y las masculinidades, así como donde se perpetúan las desigualdades de género a través de la «especialización emocional» de las mujeres en el campo amoroso (Eichenbaum y Orbach, 1987; Lagarde, 2000; Coria, 2001; Hite, 1987). Este escenario de identidades generizadas y jerarquizadas crea las condiciones de posibilidad para la «explotación del poder del amor» de las mujeres por parte de los hombres, principal vía de perpetuación de las desigualdades de género (Jónasdóttir, 1988, 1991, 2011). Esta es la raíz también de la violencia de género en el seno de la pareja (Bosch y Ferrer, 2013; Bosch, 2011; Ferrer et al., 2006; Amurrio y Larrinaga, 2010; Amurrio et al., 2010; Gómez, 2004).

En definitiva, la sociología ha ido abriendo un campo de estudio en el área del amor y las relaciones de pareja, aportando su andamiaje teórico y sus reflexiones acerca de los rasgos de la modernidad occidental de las últimas décadas. Sin embargo, las reflexiones del feminismo sobre la experiencia amorosa han sido poco reconocidas por la sociología en su conjunto, a pesar de que esta corriente de pensamiento ha sido un tema por excelencia desde su nacimiento (Jackson, 1993: 202) y a pesar también de que se proyecta como una cuestión central en los estudios feministas del siglo Xxi (Jónasdóttir y Ferguson, 2014).

Sin embargo, estas críticas feministas al amor como opresivo y legitimador de desigualdades pueden conducirnos a un callejón sin salida: «Una vez expuesta la naturaleza opresiva del amor para las mujeres, tratar de hacer exploraciones más allá parecía en el mejor de los casos banal y en el peor, ideológicamente nada razonable» (Jackson, 1993: 204) ${ }^{2}$. Es necesario abrir vías más allá de la opresión. El poder puede tener un «efecto cegador» (Medina Doménech, 2013b) que nos impida apreciar la diversidad y la heterogeneidad existentes en las prácticas cotidianas de los sujetos (Esteban et al., 2005). Este giro supone colocarnos en una posición que a priori no es cómoda, ya que la visión feminista que rechaza la matriz ideológica del amor romántico ha tendido a interpretar que las actitudes de ciertas mujeres de negociación con los sentidos del amor, el erotismo y la ilusión romántica las colocaba como "tontas culturales», «erradas», «degradantes» o cómplices con la violencia machista y el patriarcado (Felitti y Elizalde, 2015: 25).

El desafío se sitúa, como he señalado anteriormente en las reflexiones sobre la agencia, en ir más allá de planteamientos dicotómicos de víctima y agente para entender las desigualdades de género en su complejidad, al tiempo que se recuperan las posibilidades de emancipación en los discursos y en las prácticas que los sujetos articulan en su vida diaria, «astucias» y saberes (Juliano, 1998, 2006) que un excesivo foco en el poder puede hacernos pasar desapercibidos.

2. «Once the oppressive nature of love for women had been exponed, to try to explore it further seemed at best banal and at worst ideologically unsound» (Jackson, 1993: 204). 
Smart (2007), precisamente, critica la concepción feminista del amor como "falsa conciencia» por ser una simplificación excesiva, ya que no tiene en cuenta que el amor romántico puede ser una forma de escape de las mujeres. El uso de la fantasía a través de las novelas rosa se puede entender como un recurso que permita sobrellevar las relaciones desiguales de poder entre hombres y mujeres, lo cual no implica necesariamente una aceptación acrítica del contrato amoroso patriarcal. Por otra parte, en su análisis de los consultorios sentimentales durante el franquismo de los años cincuenta, Medina Doménech (2013a) aprecia saberes de las mujeres que la autora ha denominado «orquestación del amor», una serie de habilidades y de pericias que se expresaban en las reflexiones de los consultorios, en forma de elección y negociación de las condiciones del proceso y la relación amorosa, que distaban de los modelos establecidos por los saberes expertos, mostrando de esta manera que «la cultura del amor era más heterogénea de lo que cabría esperar si nos acercamos sólo al discurso más emparentado con el régimen [franquista]» (2013a: 224).

En el caso que nos ocupa de las experiencias amorosas de mujeres encarceladas, cabe preguntarse si no es necesario aplicar un utillaje para situaciones «extremas» que nos lleve a comprender las opciones «extremas» que adoptan ellas para salir adelante en contextos de gran privación emocional, relacional y subjetiva. Sigamos reflexionando sobre las articulaciones entre poder y agencia, esta vez centrándonos en las posibilidades de resistir creativamente al poder en el contexto de la prisión, pero antes paso a describir brevemente los rasgos más sobresalientes de la investigación cualitativa llevada a cabo.

\section{Investigación sobre las relaciones amorosas de las mujeres encarceladas}

Las reflexiones que aquí se realizan están basadas en la investigación titulada Relaciones amorosas de las mujeres encarceladas (De Miguel, 2016b) ${ }^{3}$. El trabajo de campo fue realizado en la prisión de Nanclares de Oca (Álava), donde se albergaba el mayor número de mujeres presas en la Comunidad Autónoma de Euskadi antes de que fuera sustituida por el Centro Penitenciario Araba en 2011. Dicha cárcel contaba con 470 celdas habitables, en que se encontraban recluidas entre 700 y 800 personas presas, de las cuales entre 60 y 70 eran mujeres que estaban localizadas en un departamento que contaba con dos módulos (Salhaketa, 2005). El trabajo de campo consistió en 49 entrevistas semiestructuradas grabadas a mujeres dentro de la prisión, junto con trabajo etnográfico de observación participante durante 14 meses (entre noviembre de 2007 y diciembre de 2008). La autorización para entrar a investigar, concedida por la Dirección General de Instituciones Penitenciarias, daba la posibilidad de acceder al departamento de mujeres con una gran flexibilidad en los tiempos

3. Investigacion de tesis doctoral que recibió el Premio Micaela Portilla a la mejor tesis feminista/de género de la UPV/EHU de 2012 y que fue financiada por el Departamento de Educación, Universidades e Investigación del Gobierno Vasco a través de una beca PDI 2008-2011. 
y en los espacios. Este hecho, junto con el visto bueno para usar la grabadora durante las entrevistas, hace de esta investigación una rara excepción en su campo y, por tanto, el material empírico resultante es prácticamente único en el panorama de estudios sobre prisiones en el Estado español. De hecho, ninguna otra autorización ha sido concedida posteriormente para investigar en la Comunidad Autónoma de Euskadi desde entonces y apenas alguna otra en todo el Estado. En cualquier caso, el estudio de las relaciones amorosas dentro de prisión supone que este trabajo sea pionero en dicho campo.

Las notas de observación participante se recogieron en el cuaderno de campo con información relativa a los acontecimientos que ocurrían en la prisión, así como también a las impresiones y a las cuestiones que resultaron llamativas o destacables, y especialmente todos aquellos aspectos que las internas comentaban en referencia a sus experiencias amorosas. Todos los nombres mencionados han sido alterados para salvaguardar la confidencialidad y el derecho a la intimidad de las participantes. La entrevista semiestructurada constaba de dos partes diferenciadas: las preguntas cerradas en cuestionario, que elaboraron información cuantitativa, y las preguntas abiertas, con información cualitativa $^{4}$. Las preguntas cerradas se referían a diversos aspectos de las vidas de las presas (datos demográficos, familia de origen, familia actual, ingresos y residencia, trayectoria laboral, educación y relación de pareja), así como a aspectos relativos a su encarcelamiento. Las cuestiones que se referían a las relaciones amorosas e íntimas, objeto central de la investigación, fueron tratadas principalmente mediante preguntas abiertas, aunque el cuestionario también contenía algunas preguntas cerradas que complementaban la información.

El perfil de las participantes en la investigación se acerca a las descripciones sociodemográficas de la literatura científica sobre las mujeres en prisión (Barañi, 2001; Almeda, 2003; Cruells e Igareda, 2005; Ribas et al., 2005; Imaz y Martín-Palomo, 2007; Imaz, 2007; Mapelli, 2012) en lo referente al gran número de mujeres pobres, así como la sobrerrepresentación de extranjeras (una de cada tres había nacido fuera de nuestras fronteras), la alta presencia de (ex)toxicómanas (casi la mitad) o el elevado porcentaje de las que pertenecían a una etnia no mayoritaria, concretamente gitanas, dado que una cuarta parte de las entrevistadas se identificaron como tales.

En cuanto a las relaciones sentimentales de las entrevistadas, casi un $80 \%$ de ellas (39 mujeres) mantenía una en el momento de la entrevista ${ }^{5}$, y aproximadamente la mitad tenía como pareja a un hombre que se encontraba en prisión en aquel momento. En este grupo de mujeres, se ha tenido en cuenta

4. De cualquier manera, la grabadora pudo recoger los comentarios realizados a propósito de cada uno de los diferentes aspectos, con lo cual las respuestas cerradas fueron completadas con las explicaciones de las participantes, lo cual dejó lugar a la captación de significados y a la contextualización de sus respuestas.

5. En la categoría de quienes mantenían una relación afectiva, he incluido a dos mujeres que manifestaron sus dudas al respecto y contestaron «no sabe», así como a otras dos mujeres que, aun manifestando que no tenían pareja, relataron algún tipo de vinculación de tipo afectivo en el momento de la entrevista. 
si se trataba de personas con las que mantenían una relación previa al encarcelamiento o si esta se había establecido durante el tiempo de prisión. En casi la mitad de los casos, la pareja que tenían en el momento de la entrevista era la misma que la de antes de ingresar en prisión, mientras que una de cada tres mujeres había establecido la relación durante el encarcelamiento, por tanto, se trataba de un hombre que también estaba recluido. Estas cifras indican la relevancia de los aspectos amorosos y relacionales en la vida carcelaria de estas mujeres, así como una cierta tendencia al emparejamiento con hombres presos (Aróstegi et al., 2008). Cuatro de ellas manifestaron haber tenido algún tipo de relación afectivo-sexual con otra mujer, siempre ceñido al contexto del encierro y sin que ello supusiera que se identificaran a sí mismas como lesbianas. Veamos el significado que otorgaban al hecho de tener pareja en el contexto de encierro a través del relato de una de las participantes.

\section{Luna habla de su pareja}

Me centro en el relato de la mujer que llamé Luna para analizar los diferentes significados de la relación amorosa dentro de prisión. En el momento de la entrevista, la edad de Luna era de 25 años y no tenía descendencia. Tal y como ella relató, su vida estuvo marcada por la falta de apoyo y la soledad, unos rasgos de permanecieron durante el encarcelamiento, solo aliviados por la fuerte amistad establecida con una compañera y con un hombre que conoció en la cárcel. Luna cuenta cómo establecieron la relación dentro de prisión:

A los 3 meses de estar él aquí me conoció a mí, en un salón de actos donde nos vemos las mujeres y los hombres. Y a mí pues, sin más, me dijo cómo se llamaba, tal y cual, pues vamos a andar de amigos, a conocernos de módulo a módulo. Él está en el módulo 1 y yo estoy en el módulo 2. Nos carteamos, los martes tenemos vis a vises.

Testimonios como el de Luna y la observación participante en el módulo de mujeres me permitieron conocer las dinámicas de establecimiento de una relación de pareja en la cárcel mixta. Mencionaré aquí brevemente unas fórmulas que he descrito con mayor extensión en De Miguel (2016b).

Tal y como cuenta Luna, el espacio por excelencia para «ligar» y conocer a personas del otro sexo en prisión suele ser el salón de actos, un recinto situado en la zona masculina que se dedica a actividades culturales varias. Estas actividades culturales en las que se encontraban hombres y mujeres eran propicios para los primeros tanteos. Por otro lado, además de las llamadas telefónicas, las cartas son la modalidad no presencial más usada tras los barrotes. El intercambio epistolar, ya sea con personas de la misma prisión o con gente del exterior, constituye todo un género carcelario. No parece exagerado afirmar que la prisión es el único contexto en que el género epistoral sigue vivo en la actualidad. Esta forma de comunicación constituye una pieza clave en la vida diaria. Tener a alguien a quien escribir y cartas por recibir con cierta asiduidad constituye uno de los entretenimientos y 
de los alicientes más importantes. Por esa razón las he denominado «el aliento de la cárcel», tanto por el oxígeno metafórico-emocional que otorgan a la persona presa, como por el constante inspirar-expirar que supone el movimiento de ida y vuelta de las misivas, el trasiego constante de enviar y recibir. Sobre estas cuestiones profundiza Sierra en su análisis de las cartas de las personas prisioneras durante la Guerra Civil y el franquismo, y precisamente hace referencia a que «escribir y recibir correspondencia era casi como respirar» (Sierra, 2016: 44).

Además de las vías oficiales de comunicación, reguladas y permitidas por la institución como la comunicación por locutorio o los encuentros vis a vis, ya sean familiares o íntimos, existen otras vías secundarias y complementarias para la comunicación que resultan llamativas para la mirada extraña al ambiente carcelario. Estas son el contacto celda a celda y las "pilas». Por la propia configuración del departamento de mujeres, un espacio específico dentro del complejo de hombres, algunos lugares eran adyacentes a los módulos masculinos y permitían cierto contacto a través de las ventanas de las celdas o del muro de uno de los patios. Las mujeres que estaban alojadas en compartimentos orientados hacia el módulo de hombres se comunicaban con ellos a voces o usaban un espejo con el que intentaban ver a la otra persona. La comunicación de muro a muro del patio se producía mediante el método de las pilas, que eran usadas para enviar mensajes pegados con cinta adhesiva que eran lanzados de un lado al otro del muro. He denominado a esta modalidad «los SMS de la cárcel», ya que solían ser mensajes cortos y tenían la virtualidad de la inmediatez, algo que las cartas no podían proporcionar. Estas vías de comunicación distintas muestran nuevamente la porosidad de la prisión y las diferentes estrategias que se ponen en marcha para traspasar los muros. De esta manera, la búsqueda de encuentro se abre paso e intenta neutralizar la lógica de separación y desencuentro, intrínseca a la institución carcelaria.

Siguiendo con Luna, se aprecia que, en las prácticas amorosas, se entrelazan íntimamente apoyo emocional y material, aspectos muy importantes para la supervivencia cotidiana tras las rejas:

Llevo 2 años y 3 meses [con él]. Llevo 2 años y 6 meses presa. Y estoy con él. Él al principio trabajaba, estaba en talleres, me mandaba peculio [dinero], me ayudaba, y le decía a su hermana para que me metiera ropa. Lleva muchos años aquí dentro, lleva aquí 11 años, ahora está saliendo ya de permisos y pues lo poco que tiene pues me lo da a mí.

El apoyo material, pues, es una forma de cuidado y de expresión de amor que se ve muy acentuada en el contexto carcelario, donde algunas personas se encuentran en una situación de escasez importante debida a la falta de apoyo, como es el caso de nuestra protagonista.

Es lo único que tengo, a él, a él.

Pasar de no tener vínculos significativos con nadie a tener un vínculo con alguien supone un salto cualitativo muy importante. Siguiendo a Illouz y a su 
teoría del amor como fuente de validación del yo, podemos interpretar que esta inserción en el marco amoroso supone también pasar de no ser nadie socialmente a ser alguien. Ello proporciona participar en el horizonte utópico compartido, con lo cual es posible contar con un anclaje de inclusión social de primer orden. Esto puede ser interpretado, también, como un recurso privilegiado para atenuar de manera significativa el estigma, la identidad deteriorada de ser una mujer delincuente. Es decir, pasar de ser una no-mujer a ser una mujer en el marco de configuración de subjetividades de género por excelencia.

El amor en prisión proporciona una motivación para levantarse cada día, el empuje para afrontar las duras condiciones carcelarias, la ilusión para proyectarse hacia un futuro esperanzado, así como el apoyo material para poder sobrellevar con menos penuria las estrecheces económicas en que se ve la mayoría de presas.

El único día de la semana son los martes que estoy con él. Es cuando desconecto de que estoy en la cárcel. Por lo demás, todos los días lo mismo, tiradas en el patio.

Estas palabras de Luna expresan la dimensión del amor como «escape»y como el recurso para huir de una realidad penosa y rutinaria, para tener un «encantamiento». Los martes, el día de los encuentros íntimos, constituyen los únicos días significativos para ella, puesto que se disrumpen las lógicas carcelarias de desencuentro y hastío. De esta manera, la compañía, el apoyo moral y la ilusión que brinda una pareja son pivotes básicos para soportar la dureza de la prisión.

Lo estoy llevando bien porque yo quiero, porque está ahí mi chaval y es él el que me da fuerzas. Y si no fuese por los consejos que él me da desde el principio, yo no estaría aquí, estaría en un primer grado que no sales nada, solo sales una hora al día de la celda.

Pero no solo ofrece recurso para el presente, sino tambien la posibilidad de realizar un proyecto de cara al futuro:

Ojalá me dure y me cumpla con lo que nosotros tenemos pensado. Que llevamos dos años y pico juntos ya. Ojalá sea todo como me dice. Si es así, yo gozando pero, sino, sola, sola y sin nadie.

\section{Conclusiones}

En este artículo, he intentado responder a dos preguntas. Primero, si son posibles formas de resistencia y agencia por parte de las mujeres en contextos de encierro. Y segundo, si el amor de pareja es un resorte sobre el que articular esta resistencia al poder con marcados rasgos de género de la institución penitenciaria. La respuesta a ambas preguntas es afirmativa. Es posible ejercer la agencia ante el poder disciplinario de la prisión siempre y cuando entendamos el poder no como algo estático y dado de una vez por todas sino como 
algo que se ejerce en relación y se recrea constantemente. En este sentido, los significados y la identidad (ya sea con sus connotaciones positivas o con sus connotaciones negativas de estigma) son aspectos que se están negociando de manera habitual y, frente a ello, las mujeres resisten tomando los recursos emocionales disponibles que les permiten reformular los significados identitarios e introducir disrupciones en las lógicas de encierro.

El amor de pareja tiene un papel importante en ese contexto, dado que permite insertarse en un marco de sentido socialmente compartido, donde se sale desde la invisibilidad a la participación en una utopía social; donde están presentes valores de libertad, abundancia, salvación, huida de la realidad. Unos valores que cobran una fuerza especial en un contexto caracterizado por la falta de libertad, la escasez material y emocional, y una realidad penosa según la cual las personas están "condenadas» penal, social y subjetivamente. Dentro de prisión, el amor se puede entender como «liberación» en sentido metafórico, pero también podemos contar con otros significados.

La experiencia amorosa no solo facilita superar las penurias de la prisión ("the pains of imprisonment») y alterar las lógicas penitenciarias de extrañamiento y distancia, sino que también permite reformular la propia identidad. El amor de pareja es una utopía social compartida, que nos permite participar en marcos de sentido comunes, lo cual es muy importante para personas que se encuentran en exclusión social. Siendo el amor una fuente de valoración del yo, este tiene una fuerza especial para las personas que socialmente reciben el mensaje de que no son nadie.

Dentro de la prisión, abundan situaciones de escasez material y emocional, por tanto, las mujeres presas toman recursos socialmente valorados para experimentar que el encarcelamiento tiene algo bueno, para sentir que existen socialmente y también para estar en contacto. Y las relaciones amorosas en la cárcel ofrecen la virtualidad de romper las lógicas de separación y desencuentro propias de la institución penitenciaria, por ello, son una transgresión. El hecho de que las personas encuentren todos los resquicios posibles tras los barrotes para comunicarse y encontrarse es expresión tanto de la porosidad de la cárcel como de la búsqueda humana de encuentro e indica que las lógicas carcelarias no tienen la última palabra.

Por otro lado, las internas performan su identidad de género a través del sentimiento intenso hacia otra persona, lo que las convierte en «seres de amor», contrarrestando la narrativa de "no-mujeres» que la institución penitenciaria despliega en su ejercicio de poder disciplinario. De esta manera, las presas realizan un ejercicio de reformulación de la feminidad que desborda definiciones hegemónicas con pretensión de universalización y que han sido construidas a través de ejes, no solo de género, sino también de clase social, procedencia étnica y nacionalidad, entre otras. Si bien está probado por la crítica feminista que el amor es un terreno por excelencia para la perpetuación de las desigualdades entre hombres y mujeres, parece demasiado simplista concluir que todo es opresión, porque llegamos a un callejón sin salida y el análisis puede obviar las negociaciones con el poder disciplinario. 
El presente artículo ha pretendido realizar una búsqueda de fórmulas que faciliten entender las opciones de mujeres que habían vivido existencias atravesadas por múltiples opresiones y que se encuentran en una situación extrema como es el encarcelamiento. No parece ajustado aplicar las mismas fórmulas de análisis para ellas que para las que gozan de mejores condiciones sociales. Pero, además, también es necesario visibilizar las formas de resistencia que ellas ejercen cotidianamente a través de su agencia interseccional.

\section{Referencias bibliográficas}

Aebi, Marcelo F.; Tiago, Melanie M. y Burkhardt, Christine (2015). SPACE I: Annual Penal Statistics. Lausana.

Almeda, Elisabet (2003). Mujeres encarceladas. Barcelona: Ariel.

- (2005). «Women's imprisonment in Spain». Punishment \& Society [en línea], 7 (2), 183-99. $<$ http://dx.doi.org/10.1177/1462474505050442>.

- (2006). «Mujeres y cárceles: Pasado y presente de las cárceles femeninas en España». En: Congreso Penitenciario Internacional: La función social de la politica penitenciaria C1. Barcelona.

- (2007). «Ejecución penal y mujer en España: Olvido, castigo y domesticidad». En: Almeda, Elisabet y Bodelón, Encarna (eds.). Mujeres y castigo: Un enfoque sociojurídico y género, 27-66. Madrid: Dykinson.

Almeda, Elisabet y Ballesteros, Ana (2015). «Políticas de igualdad en las cárceles del siglo Xxi: Avances, retrocesos y retos en la práctica del encarcelamiento femenino». Praxis Sociológica, 19, 161-86.

Almeda, Elisabet; Di Nella, Dino y Navarro, Carmen (2012). «Mujeres, cárceles y drogas: Datos y reflexiones». Oñati Socio-Legal Series, 2 (6), 122-45.

Amurrio, Mila y Larrinaga, Ane (2010). «Love and violence in learning about relationships». En: Esteban, Mari Luz y Amurrio, Mila (eds.). Feminist challenges in social sciences: Gender studies in the Basque Country. Reno, Nevada: University of Nevada, 158-73.

Amurrio, Mila; Larrinaga, Ane; Usategi, Elisa y Valle, Ana Irene de (2010). «Violencia de género en las relaciones de pareja de adolescentes y jóvenes en Bilbao». Zerbitzuan, 47 (junio), 121-34.

Aróstegi, Elisabete; Fernández, Araceli; García del Moral, Nieves y Urbano, Aurora (2008). Prisión y género: Efectos del encarcelamiento en mujeres y hombres presos y su entorno familiar. Bilbao: Zubiko.

BARAÑI (2001). Mujeres gitanas y sistema penal. Madrid: Metyel.

Bauman, Sigmund (2003). Amor liquido: Acerca de la fragilidad de los vinculos humanos. Madrid: Fondo de Cultura Económica, 2007.

BeCK, Ulrick y BeCK-Gernsheim, Elisabet (1990). El normal caos del amor. Barcelona: El Roure, 1998.

Bernard, April (2012). «The Intersectional Alternative: Explaining Female Criminality». Feminist Criminology [en línea], 8 (1), 3-19. $<$ http://dx.doi.org/10.1177/1557085112445304>.

Bhavnani, Kum-Kum y Davis, Angela (2007). «Mujeres presas: Estrategias de transformación». En: Biglia, Bárbara y SAN Martín, Conchi (eds.). Estado de Wonderbra: Entretejiendo narraciones feministas sobre las violencias de género. Madrid: Virus, 197-216. 
Bosch, Esperanza (2011). Del mito del amor romántico a la violencia contra las mujeres en la pareja. Madrid: Instituto de la Mujer.

Bosch, Esperanza y Ferrer, Victoria (2002). La voz de las invisibles: Las víctimas de un mal amor que mata. Madrid: Cátedra.

- (2013). La violencia contra las mujeres: El amor como coartada. Madrid: Anthropos.

Bosworth, Mary (1999). Engendering resistance: Agency and Power in Women's Prisons. Aldershot: Ashgate.

Bosworth, Mary y Carrabine, Eamonn (2001). «Reassessing resistance: Race, gender and sexuality in prison». Punishment and Society [en línea], 3 (4), 501-15. <http://dx.doi.org/10.1177/14624740122228393>.

Butler, Judit (1997). «Sometimiento, resistencia, resignificación». En: Butler, Judit (eds.). Mecanismos psíquicos del poder: Teorías sobre la sujeción. Madrid: Cátedra, 2001, 95-118.

- (2007). El género en disputa: El feminismo y la subversión de la identidad. Barcelona: Paidós.

Carlen, Pat (1983). Women's imprisonment: A study in social control. Londres: Routledge and Kegan Paul.

- (1988). Women, crime and poverty. Milton Keynes: Open University Press.

- (1998). Sledgehammer: Women's imprisonment at the Millenium. Londres: Macmillan Press.

Carlen, Pat y Worrall, Anne (1987). Gender, Crime and Justice. Milton Keynes: Open University Press.

Castillo, Joaquina y Ruiz, Marta (2010). «Mujeres extranjeras en prisiones españolas». RIS [en línea], 68 (2), 473-98. <http://dx.doi.org/10.3989/ris.2008.05.15>.

Comisión Global de Políticas sobre Drogas (2014). Asumiendo el control: Caminos hacia politicas de drogas eficaces [en línea]. <www.globalcommissionondrugs.org/ reports>.

Chesney-Lynd, Meda (1986). «Women and crime: The female offender». Signs: Journal of Women and Culture in Society, 2 (1), 78-96.

Chesney-Lynd, Meda y Rodriguez, Noelie (1983). "Women under Lock and Key: A View from the Inside». Prison Journal [en línea], 63, 47-65. <http://dx.doi.org/10.4135/9781483387574.n13>.

Coria, Clara (2001). El amor no es como nos lo contaron... ni como lo inventamos. Buenos Aires: Paidós.

Cruells, Marta e Igareda, Noelia (2005). Mujeres, integración y prisión. Barcelona: Aurea.

Cruells, Marta; Igareda, Noelia; Torrens, Miriam y Cruells, Eva (2004). Mujeres, integración y prisión: Informe Nacional España. Barcelona: Surt.

Cruells, Marta y Torrens, Miriam (2004). Mujeres, integración y prisión: Un análisis de los procesos de integración sociolaboral de las mujeres presas en Europa. Barcelona: Aurea.

Cruells, Marta; Torrens, Miriam e Igareda, Noelia (2005). Violencia contra las mujeres: Análisis de la población penitenciaria femenina [en línea]. Barcelona: Surt. <http://www.bizkeliza.org/fileadmin/bizkeliza/web/doc_pen/caritasSA/Estudio_ mujeres_presas_en_Catalu_a.pdf $>$.

De Miguel, Estibaliz (2008). «Actrices sociales en el escenario carcelario». En: CRUzado, Ángeles y Ortiz de Zárate, Antonia (eds.). Feminismos e interculturalidad: $V$ Congreso Internacional Audem, 113-32. Sevilla: ArCiBel.

- (2014). «Encarcelamiento de mujeres: El castigo penitenciario de la exclusión social y la desigualdad de género». Zerbitzuan, 56 (septiembre), 75-86. 
- (2015). «Mujeres usuarias de drogas en prisión». Praxis Sociológica, 19, 141-59.

- (2016a). «Mujeres, consumo de drogas y encarcelamiento: Una aproximación interseccional». Política y Sociedad [en línea], 53 (2), 529-549. $<$ http://dx.doi.org/10.5209/rev_POSO.2016.v53.n2.47421>.

- (2016b). Relaciones amorosas de las mujeres encarceladas. Bilbao: UPV/EHU Servicio Editorial.

Eichenbaum, Luise y Orbach, Susie (1987). ¿Qué quieren las mujeres? 7a ed. Madrid: Talasa, 1990.

Esteban, Mari Luz (2009). «Identidades de género, feminismo, sexualidad y amor: Los cuerpos como agentes». Política y Sociedad, 46 (1 y 2), 27-41.

- (2010). «Algunas ideas para una antropología del amor». En: ABAD, Luisa y FloRES, Juan Antonio (coords.). Congreso de Antropología: Emociones y sentimientos. Cuenca: Universidad de Castilla-La Mancha, 229-468.

- (2011). Crítica del pensamiento amoroso: Temas contemporáneos. Barcelona: Bellaterra.

Esteban, Mari Luz; Medina, Rosa y Távora, Ana (2005). «Por qué analizar el amor?: Nuevas posibilidades para el estudio de las desigualdades de género». En: Díez Mintegui, C. y Gregorio Gil, C. (coords.). Cambios culturales y desigualdades de género en el marco local-global actual: X Congreso de Antropología [en línea]. Sevilla: Fundación El Monte, 207-224. <http://hdl.handle.net/10481/22464>.

Esteban, Mari Luz y TÁvora, Ana (2008). «El amor romántico y la subordinación social de las mujeres: Revisiones y propuestas». Anuario de Psicología, 39 (1), 59-73.

Evans, Mary (2003). Love: An unromantic discussion. Oxford: Blackwell.

Felitti, Karina y Elizalde, Silvia (2015). “Vení a sacar a la perra que hay en vos”: Pedagogías de la seducción, mercado y nuevos retos para los feminismos». Revista Interdisciplinaria de Estudios de Género, 2 (julio-diciembre), 3-32.

Ferrer, Victoria; Bosch, Esperanza; Ramis, M. Carmen y Navarro, Capilla (2006). «Las creencias y actitudes sobre la violencia contra las mujeres en la pareja: Determinantes sociodemográficos, familiares y formativos». Anales de Psicología, 2 (22), 251-59.

FILI, Adriani (2013). "Women in prison: Victims or resisters? Representations of agency in women's prisons in Greece». Signs: Journal of Women in Culture and Society [en línea], 29 (1), 1-26. <http://dx.doi.org/10.1017/CBO9781107415324.004>.

Foucault, Michel (1975). Vigilar y castigar: Nacimiento de la prisión. Madrid: Siglo XXI, 1996.

Gañán, Alicia, y Gordon, Alicia (2001). La mujer drogodependiente penada en los centros penitenciarios. Madrid: Instituto de la Mujer.

Giacomello, Corina (2013). Mujeres, delitos de drogas y sistemas penitenciarios en América Latina. Londres: International Drug Policy Consortium.

Giddens, Anthony (1992). La transformación de la intimidad: Sexualidad, amor y erotismo en las sociedades modernas. Madrid: Cátedra, 2008.

GofFMAn, Erwing (1961). Internados: Ensayos sobre la situación social de los enfermos mentales. Buenos Aires: Amorrortu, 1998.

- (1963). Estigma: La identidad deteriorada. Buenos Aires / Madrid: Amorrortu, 2008. Biblioteca de Sociología.

Gómez, Jesús (2004). El amor en la sociedad del riesgo. Barcelona: El Roure.

Heidensohn, Francis (2000). Sexual Politics and Social Control. Buckinham: Open University Press. 
Hite, Shere (1987). Mujeres y amor. Nuevo informe Hite. Barcelona: Plaza y Janés, 1988.

Hochschild, Arlie (1979). «Emotion work, feeling rules and social structure». American Journal of Sociology [en línea], 85 (3), 551-75. <http://dx.doi.org/10.1086/227049>.

Huijg, Dieuwertje Dyi (2012). «Tension in Intersectional Agency: A Theoretical Discussion of the Interior Conflict of White, Feminist Activists' Intersectional Location». Journal of International Women's Studies, 13 (marzo), 3-18.

Illouz, Eva (1992). El consumo de la utopía romántica: El amor y las contradicciones culturales del capitalismo. Madrid: Katz, 2009.

- (2012). ¿Por qué duele el amor?: Una explicación sociológica. Madrid: Katz.

ImAZ, Elisabete (2007). «Mujeres reclusas, mujeres invisibles». En: BigLia, Bárbara y SAN Martín, Conchi (eds.). Estado de Wonderbra: Entretejiendo narraciones feministas sobre las violencias de género. Madrid: Virus, 189-195.

Imaz, Elisabete y Martín-Palomo, Teresa (2007). "Las otras otras: Extranjeras y gitanas en las cárceles españolas». En: Biglia, Bárbara y SAN Martín, Conchi (eds.). Estado de Wonderbra: Entretejiendo narraciones feministas sobre las violencias de género. Barcelona: Virus, 217-227.

JACKSON, Stevi (1993). «Even sociologists fall in love: An exploration in the sociology of emotions». Sociology [en línea], 27 (2), 201-20. <http://dx.doi.org/10.4135/9781446217382.n7>.

JónAsDótTir, Anna (1988). «Does sex matter to democracy?». Scandinavian Political Studies [en línea], 11 (4), 299-322. <http://dx.doi.org/10.1111/j.1467-9477.1988.tb00373.x>.

- (1991). El poder del amor: ¿Le importa el sexo a la democracia? Madrid: Cátedra, 1993.

- (2011). «¿Qué clase de poder es el poder del amor?». Sociológica, 26 (74), 247-73.

Jónasdóttir, Anna y Ferguson, Anne (eds.) (2014). Love: A question for Feminism in the Twenty-First Century. Londres / Nueva York: Routledge.

Juliano, Dolores (1992). El juego de las astucias: Mujer y construcción de modelos sociales alternativos. Madrid: Horas y Horas.

- (1998). Las que saben: Subculturas de mujeres. Madrid: Horas y Horas.

- (2006). Excluidas y marginales: Feminismos. Madrid: Cátedra.

Lagarde, Marcela (2000). "Claves feministas para las negociaciones en el amor». En: Lagarde, Marcela. Para mis socias de la vida: Claves feministas para el poderío y la autoestima de las mujeres, los liderazgos entrañables y las negociaciones en el amor. Madrid: Horas y Horas.

- (2005). Los cautiverios de las mujeres: Madresposas, monjas, putas, presas y locas. México: UNAM.

- (2008). "Amor y sexualidad: Una mirada feminista». En: Curso de verano: Sexualidades en movimiento, derechos a debate. Santander: UIMP-Universidad Internacional Menéndez Pelayo.

LANGFORD, Wendy (1999). Revolutions of the heart: Gender, power and the delusions of love. Londres: Routledge.

LARRAUri, Elena (ed.) (1994). Mujeres, derecho penal y criminología. Madrid: Siglo XXI. Lupton, Deborah (1998). "The "emotional woman" and the "unemotional man"». En: Lupton, Deborah. The emotional self: A sociocultural exploration. Londres: Sage.

Mageehon, Alexandrina (2008). "Caught up in the system: How women who have been incarcerated negotiate power». The Prison Journal [en línea], 88 (4), 473-92. <http://dx.doi.org/10.1177/0032885508325393>. 
Malloch, Margaret S. (2000). Women, drugs and custody. Winchester: Waterside Press.

Manzanos, César (1991). Cárcel y marginación social: Contribución crítica e investigación aplicada a la sociedad vasca. Donostia: Gakoa.

Manzanos, César y Balmaseda, Juana (2003). Situación de las mujeres en las cárceles del País Vasco. Vitoria-Gasteiz: Gobierno Vasco.

Mapelli Cafarena, Borja (dir.) (2012). Mujeres en las cárceles de Andalucía. Madrid: Dykinson.

Martín-Palomo, M. ${ }^{a}$ Teresa; Miranda, M. Jesús y Vega, Cristina (2005). Delitos y fronteras: Mujeres extranjeras en prisión. Madrid: Instituto de Investigaciones Feministas. UCM.

Medina Doménech, Rosa M.a (2013a). Ciencia y sabiduría del amor: Una historia cultural del franquismo: 1940-1960. Madrid: Iberoamericana.

- (2013b). "Who Were the Experts?”: The Science of Love vs. Women's Knowledge of Love During the Spanish Dictatorship». Science as Culture [en línea], 23 (2), 177-200. <http://dx.doi.org/10.1080/09505431.2013.809412>.

Messerschmidt, James (1993). Masculinities and crime: Critique and reconceptualization of theory. Lantham MD: Rowman and Littlefield.

Miranda, María Jesús (2002). "Cárceles, ¿para qué?». Politica y Sociedad, 39 (2), 377-97.

Naredo, María (2005). «¿Qué nos enseñan las nuevas reclusas?: La criminalización de la pobreza desde la situación de reclusas extranjeras y gitanas». En: MartínPalomo, M. ${ }^{a}$ Teresa; Miranda, M. ${ }^{a}$ Jesús y Vega, Cristina (eds.). Delitos y fronteras: Mujeres extranjeras en prisión. Madrid: Universidad Complutense de Madrid, 271-300.

Nari, Marcela; Fabre, Andrea; Hauser, Silvia; Calandra, Nilda; Fraguas, Noemí y FrIEDMAN, Jackeline (2000). «Me queda la palabra: Estrategias de resistencia de las mujeres encarceladas». En: NARI, Marcela y Fabre, Andrea (eds.). Voces de mujeres encarceladas. Buenos Aires: Catálogos.

Pollack, Shoshana (2008). «Reconceptualizing Women’s Agency and Empowerment». Women and Criminal Justice [en línea], 12 (1), 75-89. <http://dx.doi.org/10.1300/J012v12n01>.

Ribas, Natalia; Almeda, Elisabet y Bodelón, Encarna (2005). Rastreando lo invisible: Mujeres extranjeras en las cárceles. Barcelona: Anthropos.

Ribas, Natalia y Martínez, Alexandra (2003). «Mujeres extranjeras en las cárceles españolas». Sociedad y Economía, 5, 65-88.

Ribeiro, Raquel y Mendoza, Noehemi Orinthya (2013). «El cuerpo preso tatuado: Un espacio discursivo». Andamios: Revista de Investigación Social, 10 (23), 283-303.

Salhaketa (2005). Observando una cárcel: Nanclares de Oca-Langraitz [en línea]. Vitoria-Gasteiz: Salhaketa. Asociación de Apoyo a Presos. <http://www.nodo50. org/tortura/varios/NANCLARES-2005.pdf $>$.

ScotT, James C. (2000). Los dominados y el arte de la resistencia: Discursos ocultos. México: Era.

Secretaría General de Instituciones Penitenciarias (2015). Informe General 2014 [en línea]. Madrid. <http:/www.institucionpenitenciaria.es/web/export/sites/default/ datos/descargables/publicaciones/Informe_General_2014_def_acc.pdf>.

Sierra, Veronica (2016). Cartas presas: La correspondencia carcelaria en la Guerra Civil y el Franquismo. Madrid: Marcial Pons. 
Smart, Carol (1977). Women, crime and criminology: A feminist critique. Londres: Routledge and Kegan Paul.

- (2007). Personal Life. Londres: Polity.

Val-Cid, Consuelo del y Viedma Rojas, Antonio (eds.) (2012). Condenadas a la desigualdad: Sistema de indicadores de discriminación penitenciaria. Madrid: Icaria.

Worrall, Anne (1990). Offending women: Female lawbreakers and the criminal justice system. Londres / Nueva York: Routledge. 